\title{
A Randomized Controlled Trial to Improve Colon Cancer Screening in Rural Family Medicine: An Iowa Research Network (IRENE) Study
}

\author{
Barcey T. Levy, PhD, MD, Yinghui Xu, MS, Jeanette M. Daly, PhD, RN, \\ and John W. Ely, MD, MSPH
}

Background: Many adults have not been screened for colon cancer, a potentially preventable cause of death.

Methods: This was a randomized controlled trial conducted between December 2008 and April 2011 to improve CRC screening in 16 rural family physician offices. Subjects due for CRC screening were randomized within each practice to 1 of 4 groups: (1) usual care; (2) physician chart reminder; (3) physician chart reminder, mailed education, CRC reminder magnet, and fecal immunochemical test (FIT) (mailed education/ FIT); or (4) all the preceding plus a structured telephone call to the patient from project staff to provide education, assess interest in screening, explain the screening tests, and address barriers (mailed education/FIT plus phone call). The main outcome was completion of any CRC screening.

Results: This study enrolled 743 patients. CRC screening was completed by $17.8 \%$ in the usual care group, $20.5 \%$ in the chart reminder group, $56.5 \%$ in the mailed education/FIT group, and $57.2 \%$ in the mailed education/FIT plus phone call group. We found no effect from the chart reminder compared with usual care (odds ratio [OR], 1.2; 95\% confidence interval [CI], 0.7-2.0); and a beneficial effect from the mailed education/FIT (OR, 6.0; 95\% CI, 3.7-9.6) and the mailed education/FIT plus phone call (OR, 6.2; 95\% CI, 3.8-9.9). Both FIT and colonoscopy rates increased significantly in both mailed education groups.

Conclusion: CRC screening rates increased significantly among patients who were overdue for screening after they received mailed educational materials and a FIT. The addition of a phone call did not further increase screening rates. (J Am Board Fam Med 2013;26:486-497.)

Keywords: Cancer Screening, Colorectal Cancer, Early Medical Intervention (Educational), Practice-based Research, Randomized Controlled Trial, Reminder Systems, Rural Health

It has been estimated that $50 \%$ to $80 \%$ of colorectal cancers (CRCs) are preventable or effectively

This article was externally peer reviewed.

Submitted 18 January 2013; revised 2 May 2013; accepted 6 May 2013.

From the Department of Family Medicine, Roy J. and Lucille A. Carver College of Medicine (BTL, YX, JMD, JWE), and the Department of Epidemiology, College of Public Health (BTL), University of Iowa, Iowa City.

Funding: Support was provided by American Cancer Society Research Scholar grant targeted-08-148-01-CPPB (BTL) and the University of Iowa Department of Family Medicine.

BTL serves as the Iowa Academy of Family Physicians Endowed Chair for Rural Research.

Conflict of interest: none declared.

Trial registration: ClinicalTrials.gov identifier: NCT01477814.

Corresponding author: Barcey T. Levy, PhD, MD, Department of Family Medicine, Roy J. and Lucille A. Carver College of Medicine and College of Public Health, University of Iowa, 200 Hawkins Drive, 01292 E Pomerantz Family Pavilion, Iowa City, IA 52242 (E-mail: barcey-levy@uiowa.edu). treated if caught early. ${ }^{1-6}$ Several organizations in the United States have guidelines for CRC screening, ${ }^{7-9}$ and the National Health Service in the United Kingdom has rolled out its screening program. ${ }^{10}$ Although screening rates are increasing, only about half to two thirds of eligible individuals in the United States and the United Kingdom have been tested for CRC. ${ }^{3,11-14}$ The purpose of this study was to determine which physician and patient reminder systems were most effective for improving CRC screening rates in rural practices. These interventions were designed to remind the physician about CRC screening and provide education to patients to motivate and facilitate their screening. ${ }^{15-19}$ Taken together, these interventions were intended to create an informed, activated patient and an informed, supported physician. ${ }^{20,21}$ This 
study compared 3 interventions with usual care for improving CRC screening rates and tested the hypothesis that screening rates would be higher with more intensive interventions.

\section{Methods}

The study was approved by the University of Iowa Institutional Review Board. Sixteen family medicine offices in the Iowa Research Network (IRENE) participated in this study. Each office received $\$ 1,000$ for providing a list of their patients in the first year and $\$ 1,000$ for each of the following 2 years of participation. Local office coordinators received \$200 for completing certification for working with human subjects. Patient participants provided written informed consent and received \$20 for completing a baseline questionnaire. Selection and recruitment details are described in detail elsewhere. ${ }^{22,23}$

\section{Patient Recruitment}

Briefly, patient recruitment took place by mailed invitation between December 2008 and April 2010. Practices provided a total of 56,015 names of patients aged 52 to 79 years, and a random sample of 8372 were invited. Patients from each office were recruited sequentially so that all patients from a given office who were selected to receive an invitation did so within the same week. Subjects were recruited using a modified Dillman technique, ${ }^{24}$ which included a pre-notice letter with a $\$ 2$ bill followed by a full packet of materials 2 weeks later. Nonresponders were sent a reminder letter 3 weeks later, followed by up to 4 reminder calls to make sure they had no questions about the study; another full packet of study materials was sent if requested. ${ }^{22}$ The invitations were mailed on practice letterhead and had the electronic signatures of all office physicians and the principal investigator.

\section{Baseline Questionnaire}

The baseline questionnaire asked about family history of CRC; whether their doctor had ever recommended CRC screening; each screening method (how recently the method was completed, reason(s) the method was used). There also were 13 questions related to barriers to screening, as well as demographic questions. The questionnaire was tested and revised after being using in a previous study of 500 partici- pants. ${ }^{12,25}$ Although they were developed independent of another questionnaire designed to assess CRC screening behaviors, many of the questions were similar. $^{26}$ The answers on the baseline questionnaire were used to determine eligibility. Subjects were considered ineligible if they reported being up to date with CRC screening by any method (fecal occult blood [FOBT] or fecal immunochemical test [FIT] in the past year, barium enema or flexible sigmoidoscopy in the past 5 years, or colonoscopy in the past 10 years) ${ }^{7-9}$ Only individuals due for CRC screening were eligible for the study because it was unnecessary to encourage screening among individuals who were already up to date. Based on self-report, the average rate of being up to date with screening across offices was $54.3 \%$ (standard deviation, $14.8 \%$ ). Colonoscopy was by far the most prevalent screening test among those excluded from the study (51.4\% were up to date with colonoscopy; standard deviation, $14.8 \%$ ), indicating that the participating practices strongly preferred colonoscopy as a screening method.

Individuals with a family history of colon cancer, ulcerative colitis, Crohn's disease, or personal history of colon cancer were not excluded. Less than $1 \%$ had a history of ulcerative colitis or Crohn's disease and less than $1 \%$ had a personal history of CRC. There were no differences in these conditions across groups.

\section{Medical Record Review}

Medical records were reviewed an average of 15 months after the initial pre-notice letter was sent (range, 13.6-19.3 months). The timing of the review was chosen to allow time for the chart reminder and other interventions to have an effect, since healthy individuals may see their physician only once each year for a health maintenance examination. The form included the number and type of office visits in the preceding 26 months, information on types and dates of all CRC screening, results of flexible sigmoidoscopy and colonoscopy, and other preventive tests. ${ }^{12} \mathrm{~A}$ team of medical record reviewers visited each office to collect the data.

\section{Randomization of Subjects}

Figure 1 illustrates the recruitment procedure and study design. Of the 8372 invitation mailings, 743 patients $(9 \%)$ returned a baseline survey with informed consent and met eligibility criteria. Eligible patients were randomized within each practice with 
Figure 1. Flow of patients through the colorectal cancer screening trial. IRENE, Iowa Research Network; FIT, fecal immunochemical test.

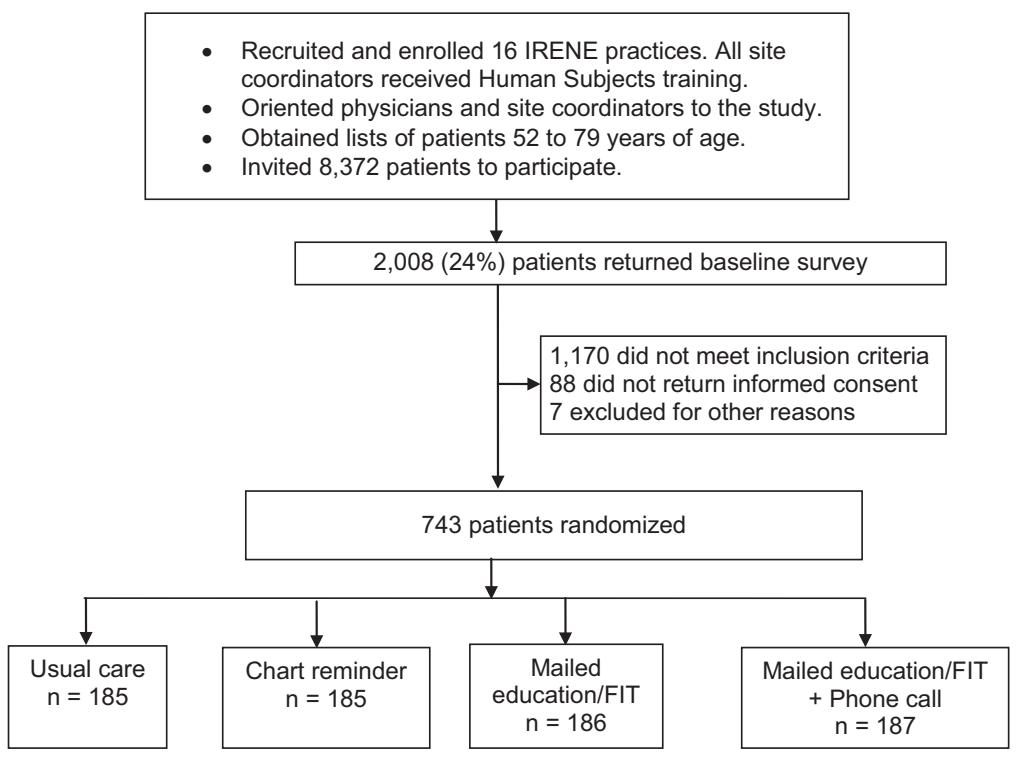

equal chance in blocks of 8 to (1) usual care; (2) physician chart reminder (Figure 2); (3) physician chart reminder, written and DVD educational materials, a refrigerator magnet to remind the subject about CRC screening (Figure 3), and a FIT with a postage-paid return envelope ("mailed education/ FIT"); and (4) all of the preceding items plus a

Figure 2. Colorectal cancer screening (CRC) reminder.

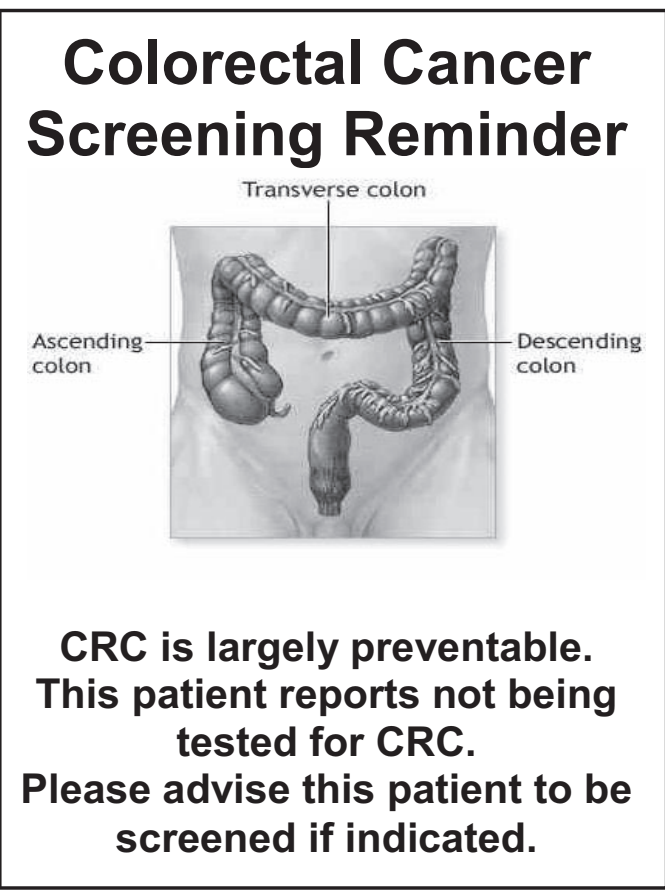

structured telephone call from project staff to provide education, assess interest in screening, explain the screening tests, address barriers and preferences, and encourage screening ("mailed education/FIT plus phone call").

Randomization was performed using a computerized random number generator. For eligible patients who provided informed consent, the chart reminder was placed or programmed in the medical record for those assigned to the chart reminder groups. For offices that used paper charts (8 offices), the chart reminder (Figure 2) was on a paper

Figure 3. Iowans Get Screened magnet.

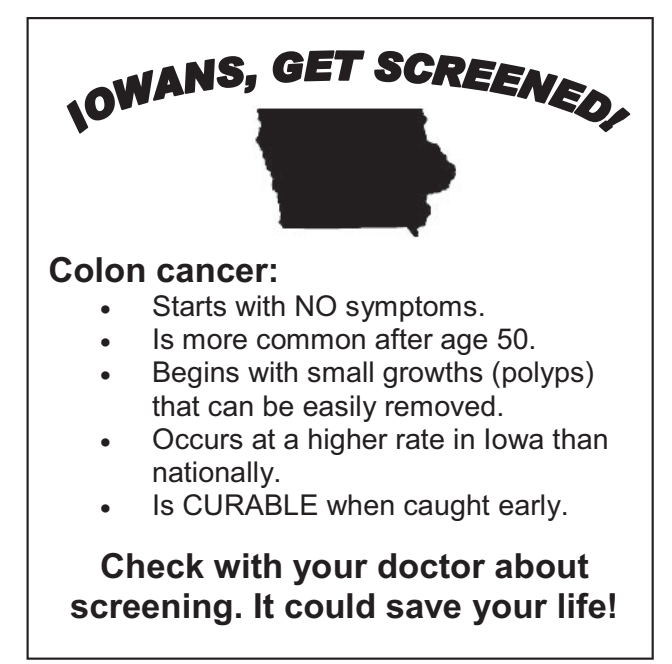


Post-it note placed in the chart by the office coordinator. The office decided the best location for the chart reminder; in most cases it was on the left side when the chart is initially opened (where immunizations and medications are recorded). For offices using electronic records, the reminder was programmed. Thus, the physician chart reminder was placed in the charts of those patients who agreed to be in the study. Site coordinators signed a sheet verifying that the reminders had been placed, and at the time of medical record review the presence of the chart reminder was noted.

The mailed educational materials included multiple items: (1) the American Cancer Society monograph and a DVD, ${ }^{27,28}$ (2) the Centers for Disease Control's Screen for Life brochure, ${ }^{29}$ and (3) a magnet developed by the investigators to remind subjects about CRC screening. ${ }^{23}$ Educational materials were mailed sequentially to patients between April 2009 and May 2010. Randomizing patients within each office allowed office differences to be balanced. ${ }^{30}$

\section{Fecal Immunochemical Tests}

The Clearview ULTRA FOB FIT (Inverness, Waltham, MA) was chosen as the FOBT. It can be used in primary care offices without access to specialized pathology services. Simulation models indicate that an annual FIT is as effective as colonoscopy every 10 years for life-years gained. ${ }^{31}$ Subjects returned the FIT to the investigators, who processed them, and results were mailed to both the patient and physician.

\section{Outcome Measures}

The primary outcome was CRC screening by any method in the 15-month interval following the initial mailed invitation. The only preplanned secondary outcome was the specific method used: FOBT (3-card FOBT), FIT, barium enema, flexible sigmoidoscopy, and/or colonoscopy. The outcomes were determined by trained medical record reviewers who were blinded to the intervention.

\section{Statistical Methods}

The analysis was based on the intention-to-treat principle and included all randomized participants. Subjects in the 4 groups were compared with respect to baseline demographics, attitudinal variables related to CRC screening, and medical record review variables using standard descriptive statis- tics. The Pearson $\chi^{2}$ test was used to compare discrete outcomes. One-way analysis of variance was used to compare continuous variables. Wilcoxon rank-sum tests were used for ordinal variables and continuous variables that did not follow a normal distribution. Subjects whose charts could not be found were considered not screened. For the questions about screening barriers, an average score was calculated by summing the individual scores and dividing by the number of questions answered. Odds ratios were calculated for differences in screening rates between the intervention groups and the usual care group. The SAS Glimmix procedure was used to account for the correlation of subjects within practices. We adjusted for prespecified patient characteristics such as age, sex, educational level, insurance status, family history of CRC, physician recommendation for CRC screening, importance of CRC screening, and average barrier score at baseline. The practice effects were specified as the random intercepts in the model. All analyses were performed using SAS version 9.2 (SAS, Inc., Cary, NC).

\section{Role of the Funding Source}

Peer reviewers for the American Cancer Society provided input on study design during the grant proposal review process. The funders had no role in data collection, analysis, or interpretation of data or in writing the report or the decision to submit the manuscript for publication.

\section{Results}

Figure 1 diagrams the study flow. Baseline questionnaires were returned by 2008 individuals (24\%). Of those who returned questionnaires, 838 (42\%) were due for CRC screening based selfreport. However, 88 did not return a signed informed consent document and 7 were ineligible for other reasons. Thus, a total of 743 participants (89\%) were enrolled in the study.

The baseline characteristics of the study population $(n=743)$ are presented in Table 1 . There were no significant differences in any characteristics across the 4 groups. The mean age was 61.1 years; $386(52 \%)$ were women, 733 (99\%) were white, $273(37 \%)$ had a high school education or less, and 51 (7\%) had no insurance.

Table 2 summarizes the medical record review for the 4 groups. There were no significant dif- 
Table 1. Demographics and Baseline Characteristics $(n=743) *$

\begin{tabular}{|c|c|c|c|c|}
\hline Variables & $\begin{array}{l}\text { Usual Care } \\
(\mathrm{n}=185)\end{array}$ & $\begin{array}{l}\text { Physician Chart } \\
\text { Reminder }(\mathrm{n}=185)\end{array}$ & $\begin{array}{l}\text { Mailed Education/FIT } \\
\qquad(\mathrm{n}=186)\end{array}$ & $\begin{array}{l}\text { Mailed Education }+ \\
\text { Phone Call }(\mathrm{n}=187)\end{array}$ \\
\hline \multicolumn{5}{|l|}{ Age (years) } \\
\hline$<65$ & $136(73.5)$ & $131(70.8)$ & $131(70.4)$ & $136(72.7)$ \\
\hline$\geq 65$ & $49(26.5)$ & $54(29.2)$ & $55(29.6)$ & $51(27.3)$ \\
\hline Female sex & $99(53.5)$ & $94(50.8)$ & $97(52.2)$ & $96(51.3)$ \\
\hline \multicolumn{5}{|l|}{ Marital status } \\
\hline Single & $27(14.6)$ & $34(18.4)$ & $26(14.0)$ & $27(14.4)$ \\
\hline Married & $145(78.4)$ & $135(73.0)$ & $143(76.9)$ & $148(79.1)$ \\
\hline Widowed & $13(7.0)$ & $14(7.6)$ & $17(9.1)$ & $11(5.9)$ \\
\hline Unknown & $0(0)$ & $2(1.1)$ & $0(0)$ & $1(0.5)$ \\
\hline Hispanic ethnicity & $3(1.6)$ & $2(1.1)$ & $2(1.1)$ & $1(0.5)$ \\
\hline \multicolumn{5}{|l|}{ Race } \\
\hline White & $182(98.4)$ & $182(98.4)$ & $183(98.4)$ & $186(99.5)$ \\
\hline Black & $2(1.1)$ & $0(0)$ & $2(1.1)$ & $0(0)$ \\
\hline Asian & $0(0)$ & $0(0)$ & $1(0.5)$ & $0(0)$ \\
\hline Other/unknown & $1(0.5)$ & $3(1.6)$ & $0(0)$ & $1(0.5)$ \\
\hline \multicolumn{5}{|l|}{ Educational level } \\
\hline High school or less & $61(33.0)$ & $69(37.3)$ & $68(36.6)$ & $75(40.1)$ \\
\hline Some college or more & $123(66.5)$ & $112(60.5)$ & $117(62.9)$ & $111(59.4)$ \\
\hline Unknown & $1(0.5)$ & $4(2.2)$ & $1(0.5)$ & $1(0.5)$ \\
\hline Uninsured & $6(3.2)$ & $14(7.6)$ & $18(9.7)$ & $13(7.0)$ \\
\hline \multicolumn{5}{|l|}{ Annual income (\$) } \\
\hline$<40,000$ & $72(38.9)$ & $61(33.0)$ & $69(37.1)$ & $71(38.0)$ \\
\hline $40,000-<80,000$ & $79(42.7)$ & $83(44.9)$ & $81(43.5)$ & $76(40.6)$ \\
\hline$\geq \$ 80,000$ & $23(12.4)$ & $24(13.0)$ & $26(14.0)$ & $31(16.6)$ \\
\hline Unknown & $11(6.0)$ & $17(9.2)$ & $10(5.4)$ & $9(4.8)$ \\
\hline Rural resident & $156(84.3)$ & $152(82.2)$ & $151(81.2)$ & $150(80.2)$ \\
\hline \multicolumn{5}{|l|}{ Family history } \\
\hline Immediate family member & $13(7.0)$ & $19(10.3)$ & $22(11.8)$ & $24(12.9)$ \\
\hline More distant relative & $23(12.4)$ & $18(9.7)$ & $26(14.0)$ & $16(8.6)$ \\
\hline $\begin{array}{l}\text { Patient reported doctor had recommended } \\
\text { CRC screening }\end{array}$ & $91(49.2)$ & $84(45.4)$ & $101(54.3)$ & $97(51.9)$ \\
\hline Mean barrier scores (SD) & $1.4(0.9)$ & $1.4(0.8)$ & $1.3(0.8)$ & $1.3(0.9)$ \\
\hline $\begin{array}{l}\text { Subject rated CRC screening highly important } \\
(8-10 \text { on scale of } 1-10)\end{array}$ & $103(55.7)$ & $105(56.8)$ & $110(59.1)$ & $105(56.1)$ \\
\hline
\end{tabular}

${ }^{*}$ Data are $\mathrm{n}(\%)$ unless otherwise indicated. There were no significant differences for the variables in this table among the 4 groups. CRC, colorectal cancer; FIT, fecal immunochemical test; SD, standard deviation.

ferences in clinical measurements across the 4 groups. The mean body mass index was 30.9 (standard deviation, 6.8). There were 541 (73\%) who had at least one office visit during the follow-up interval. Lipid tests were completed by $491(66 \%)$ in the past 5 years. Among women, 180 of $386(47 \%)$ had a mammogram and 17 of $88(19 \%)$ of those who were 65 years older had a bone density test in the past 26 months. Among men, 155 of 357 (43\%) had a prostate-specific antigen test completed in the past 26 months.

Table 3 summarizes the comparisons of the primary and secondary outcomes. For the primary outcome of any CRC tests completed, there was no significant difference between the chart reminder (38 of 185 patients; $20.5 \%$ ) and usual care group (33 of 185 patients; $17.8 \%$ ). The CRC screening rate in the mailed education/FIT group was 105 of 186 patients $(56.5 \%)$, and in the mailed education/ FIT plus phone call group was 107 of 187 patients (57.2\%) $(P<.0001$ for each comparison when compared with usual care). Compared with usual care, the odds of being screened were significantly higher in both groups that received mailed education (mailed education/FIT: odds ratio [OR], 6.0; $95 \%$ confidence interval [CI], 3.7-9.6; and mailed 
Table 2. Medical Record Review Variables*

\begin{tabular}{|c|c|c|c|c|}
\hline Variables & $\begin{array}{l}\text { Usual Care } \\
(\mathrm{n}=177)\end{array}$ & $\begin{array}{c}\text { Physician Chart } \\
\text { Reminder }(\mathrm{n}=173)\end{array}$ & $\begin{array}{l}\text { Mailed Education/FIT } \\
\qquad(\mathrm{n}=178)\end{array}$ & $\begin{array}{l}\text { Mailed Education/FIT + } \\
\text { Phone Call }(\mathrm{n}=176)\end{array}$ \\
\hline Mean body mass index (SD) & $31.1(7.2)$ & $31.5(7.5)$ & $30.2(6.3)$ & $30.6(6.3)$ \\
\hline $\begin{array}{l}\text { Visits ( } 26 \text { months before the initial } \\
\text { mailing) }\end{array}$ & $4(2,6)$ & $4(2,7)$ & $4(2,7)$ & $4(1,7)$ \\
\hline $\begin{array}{l}\text { Annual visits ( } 26 \text { months before } \\
\text { prenotice date) }\end{array}$ & $0(0,1)$ & $0(0,1)$ & $1(0,1)$ & $1(0,1)$ \\
\hline Medical conditions & $2(1,4)$ & $3(2,4)$ & $3(2,4)$ & $3(2,4)$ \\
\hline $\begin{array}{l}\text { Medications (prescription and over the } \\
\text { counter) }\end{array}$ & $5(3,8)$ & $5(2,7)$ & $6(3,9)$ & $5(3,8)$ \\
\hline $\begin{array}{l}\text { Any visit during the } 15 \text { month follow-up } \\
\text { time period, } \mathrm{n}(\%)\end{array}$ & $134(75.7)$ & $133(76.9)$ & $139(78.1)$ & $135(76.7)$ \\
\hline Any visit in past 26 months, $\mathrm{n}(\%)$ & $158(89.3)$ & $150(86.7)$ & $157(88.2)$ & $151(85.8)$ \\
\hline $\begin{array}{l}\text { Annual exam visit in past } 26 \text { months, } \\
n(\%)\end{array}$ & $80(45.2)$ & $83(48.0)$ & $93(52.3)$ & $91(51.7)$ \\
\hline Cholesterol in past 5 years, $\mathrm{n}(\%)$ & $126(71.2)$ & $126(72.8)$ & $128(71.9)$ & $111(63.1)$ \\
\hline $\begin{array}{l}\text { Mammogram in past } 26 \text { months, (386 } \\
\text { women), } \mathrm{n}(\%)\end{array}$ & $50(52.1)$ & $38(43.7)$ & $51(54.3)$ & $41(46.1)$ \\
\hline $\begin{array}{l}\text { Bone density in past } 26 \text { months ( } 88 \\
\text { women } \geq 65 \text { years old), } \mathrm{n}(\%)\end{array}$ & $5(19.2)$ & $4(18.2)$ & $3(16.7)$ & $5(22.7)$ \\
\hline $\begin{array}{l}\text { PSA level in past } 26 \text { months ( } 357 \text { men), } \\
\mathrm{n}(\%)\end{array}$ & $36(44.4)$ & $46(53.5)$ & $34(40.5)$ & $39(44.8)$ \\
\hline
\end{tabular}

Values are median (25th percentile, 75 th percentile) unless otherwise indicated. There were no significant differences for the variables in this table among the 4 groups.

${ }^{*}$ Only 704 subjects had charts available for review. The total number of available charts was used as the denominator.

FIT, fecal immunochemical test; PSA, prostate-specific antigen; SD, standard deviation.

education/FIT plus phone call: OR, 6.2; 95\% CI, 3.8-9.9). When comparing practices using electronic reminders versus paper reminders, there was no difference in the main outcome of any CRC screening. Figure 4A shows the cumulative screening rates over time in the 4 groups. Figure $4 \mathrm{~B}$ shows the cumulative rates of FIT or colonoscopy in each group. FIT screening was the major contributor to screening in the 2 mailed education groups.

Rates of colonoscopy were significantly higher than usual care in each of the 2 groups that received

Table 3. Comparisons of Primary and Secondary Outcomes, with Usual Care as Reference Group

\begin{tabular}{|c|c|c|c|c|c|}
\hline Tests Completed & $\begin{array}{l}\text { Usual Care } \\
(\mathrm{n}=185)\end{array}$ & $\begin{array}{l}\text { Physician Chart } \\
\text { Reminder } \\
(\mathrm{n}=185)\end{array}$ & $\begin{array}{l}\text { Mailed Education/FIT } \\
\qquad(\mathrm{n}=186)\end{array}$ & $\begin{array}{l}\text { Mailed Education/FIT } \\
+ \text { Phone Call }(\mathrm{n}=187)\end{array}$ & Overall $P$ \\
\hline \multicolumn{6}{|l|}{$\begin{array}{l}\text { Any CRC test completed during the } \\
15 \text {-month follow-up period }\end{array}$} \\
\hline $\mathrm{n}(\%)$ & $33(17.8)$ & $38(20.5)$ & $105(56.5)$ & $107(57.2)$ & $<.0001$ \\
\hline OR $(95 \% \mathrm{CI})$ & Reference & $1.2(0.7-2.0)$ & $6.0(3.7-9.6)$ & $6.2(3.8-9.9)$ & \\
\hline \multicolumn{6}{|l|}{ Colonoscopy } \\
\hline $\mathrm{n}(\%)$ & $22(11.9)$ & $33(17.8)$ & $41(22.0)$ & $36(19.3)$ & .073 \\
\hline OR (95\% CI) & Reference & $1.6(0.9-2.9)$ & $2.1(1.2-3.7)$ & $1.8(1.0-3.1)$ & \\
\hline $\begin{array}{l}\text { Take home fecal occult blood test } \\
\qquad(\times 3), \mathrm{n}(\%)\end{array}$ & $5(2.7)$ & $5(2.7)$ & $4(2.2)$ & $3(1.6)$ & .875 \\
\hline Flexible sigmoidoscopy, n (\%) & $1(0.5)$ & $0(0)$ & $0(0)$ & $0(0)$ & .389 \\
\hline Barium enema, n (\%) & $0(0)$ & $0(0)$ & $0(0)$ & $0(0)$ & \\
\hline FIT returned to investigators, $\mathrm{n}(\%)^{*}$ & - & - & $84(45.2)$ & $91(48.7)$ & .498 \\
\hline
\end{tabular}

*No fecal immunochemical test (FIT) was mailed to the usual care or chart reminder groups.

CI, confidence interval; CRC, colorectal cancer; OR, odds ratio. 
Figure 4. A: Cumulative percentage screened with any method by study group. B: Cumulative percentage screened with fecal immunochemical test (FIT) or colonoscopy (CS) by study group.
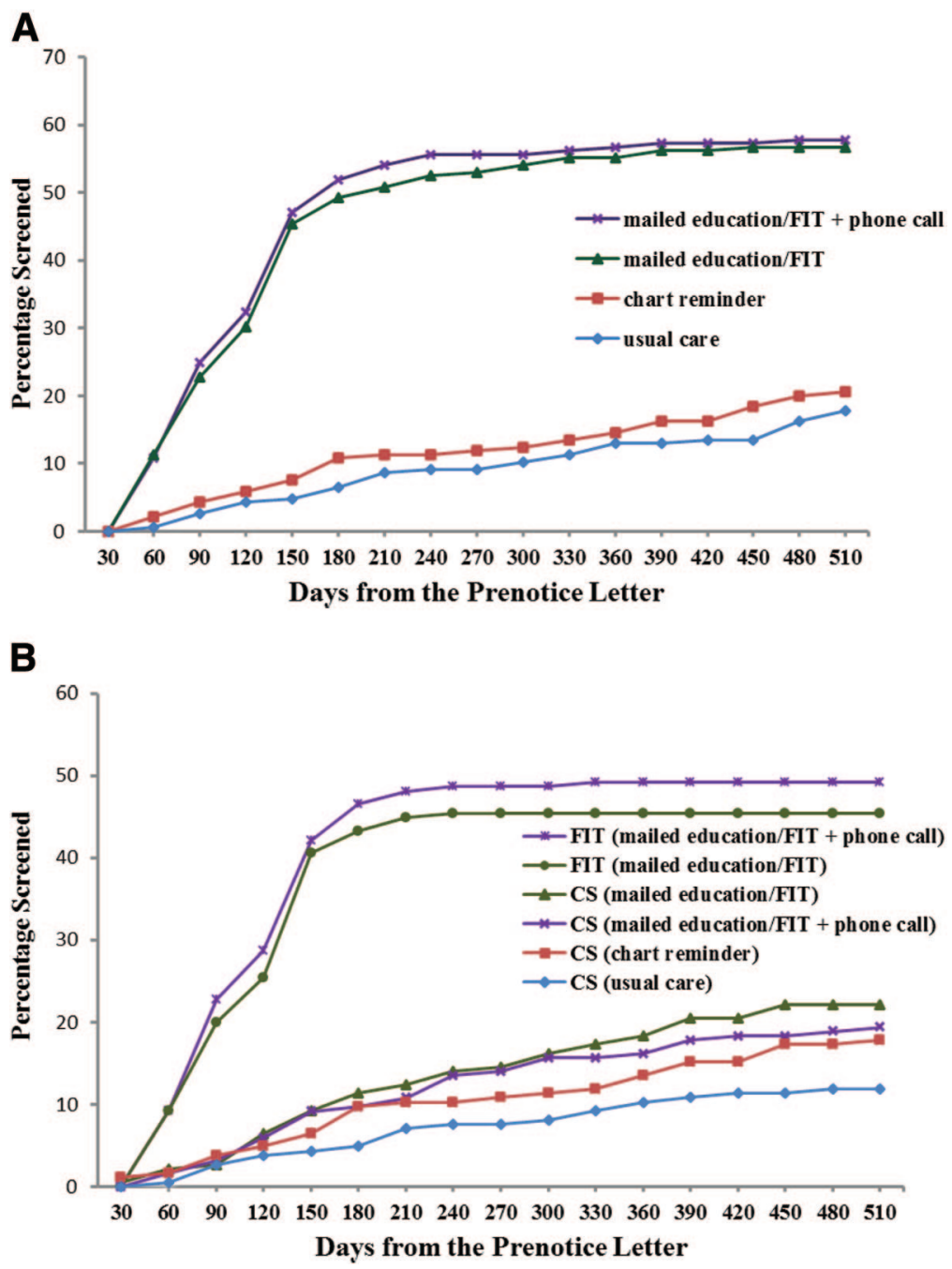

mailed education $(22 \%$ vs $11.9 \% ; P=.009$ for mailed education/FIT vs usual care and $19.3 \%$ vs $11.9 \% ; P=.050$ for the mailed education/FIT plus phone call vs usual care). Although the $17.8 \%$ colonoscopy rate in the chart reminder group was higher than that in the usual care group, this difference did not reach statistical significance $(P=$ $.108)$.

Table 4 compares the intervention effects while controlling for prespecified covariables that might affect screening. The ORs for the 2 groups that received mailed education were significant and nearly identical to those found in the unadjusted analyses. Other covariables associated with CRC screening were doctor recommendation of CRC screening (as reported on the baseline questionnaire; OR, 1.7; 95\% CI, 1.2-2.4), greater patient- perceived importance of CRC screening (OR, 1.8 [scores of $8-10$ vs $1-7$ ]); 95\% CI, 1.2-2.5), and having a physical examination during the follow-up period (yes vs no; OR, 1.5; 95\% CI, 1.03-2.1).

\section{Discussion}

In this randomized controlled trial, compared with usual care, we found that the overall CRC screening rates by any method increased significantly in the 2 groups that received nontailored, mailed patient education that included a FIT. Screening rates increased for both FIT and colonoscopy in these 2 groups, but FIT was the major contributor to screening. In addition, rates of colonoscopy increased in all groups compared with usual care but 
Table 4. Predictors of Becoming Up To Date with Colorectal Cancer (CRC) Screening* Using Prespecified Covariables

\begin{tabular}{|c|c|c|c|}
\hline Outcome variable (Any tests completed) & Odds Ratio & $95 \% \mathrm{CI}$ & $P$ \\
\hline Intercept & - & - & .008 \\
\hline Chart reminder vs usual care & 1.23 & $0.71-2.11$ & .46 \\
\hline Mailed education/FIT vs usual care & 6.29 & $3.80-10.43$ & $<.0001$ \\
\hline Mailed education/FIT + phone call vs usual care & 6.38 & $3.86-10.54$ & $<.0001$ \\
\hline Sex (female vs male) & 1.06 & $0.75-1.49$ & .76 \\
\hline Education (high school or less vs college) & 1.00 & $0.70-1.42$ & .99 \\
\hline Insurance (yes vs no) & 1.26 & $0.62-2.58$ & .53 \\
\hline Age (per 1-year increase) & 1.01 & $0.98-1.03$ & .57 \\
\hline Family history of CRC (immediate or distant) & 1.45 & $0.95-2.20$ & .08 \\
\hline Patient reported doctor had recommended CRC screening (yes vs no) & 1.66 & $1.16-2.37$ & .006 \\
\hline Importance of CRC screening to your health ${ }^{\dagger}$ & 1.76 & $1.23-2.52$ & .002 \\
\hline Baseline average barrier score $e^{\ddagger}$ & 0.84 & $0.67-1.03$ & .10 \\
\hline Had a physical exam visit during follow-up (yes vs. no) & 1.48 & $1.03-2.11$ & .03 \\
\hline
\end{tabular}

*With the SAS Glimmix procedure, which controls for the clustering of patients within practices.

${ }^{\dagger}$ Scores of $8-10$ vs $1-7$, with higher numbers indicating more importance.

${ }^{\ddagger}$ Per an increase of 1 in average barrier score, the odds ratio was 0.84 given other variables remain constant in the model. (There were 13 questions about barriers, each of which was scored from $0-5$, with higher scores indicating more barriers.)

CI, confidence interval; FIT, fecal immunochemical test.

increased significantly only in the 2 groups that received mailed education. Physician chart reminders alone did not result in a statistically significant increase in overall screening or in colonoscopy. An additional telephone reminder designed to educate the patient, assess barriers, and move the patients along the stages of change toward screening ${ }^{32}$ had no beneficial effect over mailed education alone.

The effect of physician chart reminders has varied in other studies. We searched PubMed citations dated March 1987 through August 2012 that were limited to English language. Using the terms randomized trial and chart reminder and found 3 articles that assessed chart reminders to improve CRC screening. ${ }^{33-35}$ In one of these studies, the use of office support systems, including chart reminders, increased the odds of completing mammography and FOBTs, ${ }^{33}$ whereas in another study, use of a Comprehensive Annotated Reminder Tool did not increase FOBT but did increase many other services targeted by the tool. ${ }^{34}$ Physician chart reminders did not improve CRC screening in another study of more than 20,000 patients. ${ }^{35}$ Two recent Cochrane reviews of physician chart reminders have shown minimal to moderate effects. ${ }^{36,37}$ Computer reminders achieved an improvement of $3.8 \%$ (interquartile range [IQR], $0.4-16.3 \%$ ) for ordering tests. ${ }^{36}$ Our chart reminder increased colonoscopy testing by $5.9 \%$ over usual care (not significant), which is similar to the median improvement in the review by Shojania et $\mathrm{al}^{36}$ but did not improve overall rates of CRC screening. Implementing reminders alone improved care by $11.2 \%$ (IQR, 6.5-19.6\%); implementing reminders in addition to another intervention led to improved rates of $4 \%$ (IQR, $3-6 \%){ }^{37}$ Providing an explanation of the content on the reminder seemed to improve the effect (median, $12.0 \%$ for explanation vs $4.2 \%$ for no explanation). ${ }^{37}$ Our reminders provided a concise explanation of the need for CRC screening in asymptomatic individuals.

In contrast to many studies, our study included a usual care control group and a detailed medical record review to ascertain all CRC screening completed by patients. Nontailored existing educational materials from reputable national organizations were used because we wanted to generalize our findings to a wide range of practice settings. ${ }^{28,29}$ These materials informed individuals about the 4 major accepted methods used to screen for CRC. ${ }^{7-9}$ Our refrigerator magnet and invitational mailing emphasized that CRC can occur in the absence of symptoms. The 2 groups that received mailed education plus FIT had rates of CRC screening of more than $56 \%$ in the 15 months following the initial mailing, which was significantly greater than the usual care group. 
In a model that controlled for prespecified potential confounding variables, the ORs for the mailed intervention were similar to the unadjusted odds ratios. The increase in CRC screening in the 2 groups receiving mailed education resulted from both an increase in colonoscopy and return of the mailed FIT, although return of the FIT contributed substantially to the high screening rates in these groups. The popularity of the FIT in this study likely resulted from the inclusion of this test in the mailed materials and the clear directions for completion, which allowed patients to complete this test in the privacy of their home and return it to the investigators without the need for a medical appointment. Other studies have been conducted using mailed FOBTs, but, in contrast to our study, these studies have not ascertained any CRC screening using medical record review. ${ }^{38-41}$ Studies conducted in the context of population-based screening programs in Great Britain or the Netherlands showed that FOBTs, educational materials, and a letter signed by the patient's physician resulted in screening rates ranging from $55 \%$ to $65 \% .^{42-44}$ Randomized controlled trials in practices where a mailed FOBT was used gave rates of returned FOBTs of $27 \%$ to $48 \%,{ }^{45} 33 \%$ to $48 \%,{ }^{38} 29 \%$ to $36 \%,{ }^{46}$ and $60 \% .{ }^{47}$

Although the telephone call was designed to assess patient barriers and move patients through the stages of change, ${ }^{32}$ our telephone call did not increase screening rates. This finding contrasts with a study of minority and low-income women in New York City, where telephone support increased rates of Papanicolaou tests, mammography, and CRC testing. ${ }^{48}$ Another study tested various interventions to increase screening using FOBT and randomized patients to usual care, a standard mailed intervention, a tailored mailed intervention, or a tailored intervention plus telephone reminder. ${ }^{38}$ FOBT rates increased to $44 \%$ to $48 \%$ in all intervention groups but were not significantly different from each other, indicating that, similar to our study, the telephone call had no added effect. ${ }^{38}$

We found a few practice-based studies that assessed strategies similar to ours. One study included 21,860 patients from 14 ambulatory practices in the Harvard Vanguard Medical Associates system; the patients all were overdue for CRC screening and were randomized to mailed education with 3 guaiac FOBT cards versus no mailed education. The study found overall CRC screening rates in their intervention group at follow-up to be slightly lower than the rates we found $(44 \%$ for mailed group vs $38 \%$ for the group that did not receive a mailing; $P<.001) .{ }^{35}$ Similar to our study, these investigators found no effect of chart reminders to physicians and the main increase in screening was due to FOBT completion. ${ }^{35}$ Ling et $\mathrm{al}^{49}$ conducted a randomized controlled trial of 10 primary physician group practices affiliated with the University of Pittsburgh. Enhanced office and patient management led to CRC screening rates of more than $50 \%$ among patients who were due for screening, and a tailored letter made no difference. ${ }^{49} \mathrm{We}$ provided substantial support to offices with our direct-to-patient mailed education and other reminders, with final screening rates above $56 \%$ in the 2 intervention groups that received mailed education plus a FIT.

Strengths of this study include the "real-world" setting of family physician practices that randomized patients who were due for screening. These patients attended one of 16 rural family physician practices, and medical record review was used as the gold standard, in contrast to other studies that relied on self-report ${ }^{40,41}$ or did not include a usual care group. ${ }^{49,50}$ By including a usual care control group, we were able to control for secular trends in screening during the study period. The wording in the cover letter to patients was designed to be easily understood, emphasize the recommendation for screening everyone older than age 50, and explain the need for screening even in the absence of symptoms. Letters were mailed on the practice letterhead and signed by all the physicians in the practice, which may have lent credibility to the information and indicated the support of the patient's personal physician. Given the increase in colonoscopy rates in the 2 groups that received mailed education, it seems that providing written information stimulated some individuals to receive a colonoscopy. The educational materials were not tailored, eliminating significant time and expense in developing a personalized tailored intervention for each participant and making this type of intervention more easily expanded to a broader population.

Study limitations include the limited geographic area (rural Iowa), the homogeneous nature of the patient population, the inability to know what part of the complex intervention and mailed materials were responsible for improved screening rates, the lack of information about how to incorporate the 
intervention from an economic perspective (who will pay for this intervention), and participation bias in that individuals with no interest in CRC screening would likely not agree to participate.

Because CRC screening is not controversial and saves lives, ${ }^{5-9,14,31,51}$ future studies should attempt to conduct and evaluate interventions to improve CRC screening without receiving individual informed consent, similar to the approach used by Sequist et $\mathrm{al},{ }^{35}$ so a nonbiased sample can be obtained. This article supports the notion that providing offices with support for CRC screening leads to improved CRC screening rates. ${ }^{23,35,49,52-54}$

\section{Interpretation}

It has been estimated that $50 \%$ to $80 \%$ of CRCs could be prevented with appropriate screening. ${ }^{1-6}$ Screening rates are lower in socioeconomically disadvantaged and rural populations. ${ }^{55-57} \mathrm{~A}$ physician chart reminder did not increase screening compared with usual care. Each of the groups receiving mailed, nontailored educational materials plus a FIT had final CRC screening rates of more than $56 \%$, a statistically significant improvement over usual care. This increase was largely due to return of the FIT, but colonoscopy rates increased as well. Our mailed packet included many types of education and we are not able to separate which aspects of our bundled education packet worked. The telephone call added to mailed education did not improve screening rates, but more intensive telephone interventions did improve screening in other studies.

Organizations and practices seeking to improve screening rates should consider mailing nontailored, easily understood educational materials and postage-paid returnable FITs to patients who are due for CRC screening. Our health care system should provide coverage for CRC screening that includes appropriate follow-up testing.

\section{References}

1. Subramanian S, Bobashev G, Morris RJ. Modeling the cost-effectiveness of colorectal cancer screening: policy guidance based on patient preferences and compliance. Cancer Epidemiol Biomarkers Prev 2009;18:1971-8.

2. Vogelaar I, van Ballegooijen M, Schrag D, et al. How much can current interventions reduce colorectal cancer mortality in the U.S.? Mortality projections for scenarios of risk-factor modificat- ion, screening, and treatment. Cancer 2006;107: 1624-33.

3. National Center for Chronic Disease Prevention and Health Promotion, Division of Cancer Prevention and Control, Centers for Disease Control and Prevention (CDC). Colorectal cancer: 1 in 3 adults are not being screened. July 2011. Available from: www. cdc.gov/VitalSigns/pdf/2011-07-vitalsigns.pdf. Accessed July 13, 2011.

4. National Cancer Institute. Colorectal cancer screening (PDQ). Available from: http://www.cancer.gov/ cancertopics/pdq/screening/colorectal/HealthProfessional. Accessed July 13, 2011.

5. Zauber AG, Winawer SJ, O'Brien MJ, et al. Colonoscopic polypectomy and long-term prevention of colorectal-cancer deaths. N Engl J Med 2012;366: 687-96.

6. Telford JJ, Levy AR, Sambrook JC, et al. The costeffectiveness of screening for colorectal cancer. Can Med Assoc J 2010;182:1307-13.

7. U.S. Preventive Services Task Force. Screening for colorectal cancer: U.S. Preventive Services Task Force recommendation statement. Ann Intern Med 2008;149:627-37.

8. Levin B, Lieberman DA, McFarland B, et al. Screening and surveillance for the early detection of colorectal cancer and adenomatous polyps, 2008: a joint guideline from the American Cancer Society, the US Multi-Society Task Force on Colorectal Cancer, and the American College of Radiology. Gastroenterology 2008;134:1570-95.

9. Smith RA, Cokkinides V, Brooks D, Saslow D, Brawley OW. Cancer screening in the United States, 2010: a review of current American Cancer Society guidelines and issues in cancer screening. CA Cancer J Clin 2010;60:99-119.

10. National Health Service. NHS Bowel Cancer Screening Programme. Available from: http://www. cancerscreening.nhs.uk/bowel/index.html. Accessed August 27, 2012.

11. Yeazel M, Church TR, Jones RM, et al. Colorectal cancer screening adherence in a general population. Cancer Epidemiol Biomarkers Prev 2004;13:654-7.

12. Levy BT, Dawson J, Hartz AJ, James PA. Colorectal cancer testing among patients cared for by Iowa family physicians. Am J Prev Med 2006;31:193-201.

13. Crawford ND, Jones CP, Richardson LC. Understanding racial and ethnic disparities in colorectal cancer screening: Behavioral Risk Factor Surveillance System, 2002 and 2004. Ethn Dis 2010;20: 359-65.

14. Logan RF, Patnick J, Nickerson C, et al. Outcomes of the Bowel Cancer Screening Programme (BCSP) in England after the first 1 million tests. Gut 2012; 61:1439-46.

15. Stone EG, Morton SC, Hulscher ME, et al. Interventions that increase use of adult immunization and 
cancer screening services: a meta-analysis. Ann Intern Med 2002;136:641-51.

16. Hibbard JH, Stockard J, Mahoney ER, Tusler M. Development of the Patient Activation Measure (PAM): conceptualizing and measuring activation in patients and consumers. Health Serv Res 2004;39: 1005-26.

17. Hollon MF. Direct-to-consumer advertising: a haphazard approach to health promotion. JAMA 2005; 293:2030-3.

18. Kravitz RL, Epstein RM, Feldman MD, et al. Influence of patients' requests for direct-to-consumer advertised antidepressants: a randomized controlled trial. JAMA 2005;293:1995-2002.

19. Shea S, DuMouchel W, Bahamonde L. A metaanalysis of 16 randomized controlled trials to evaluate computer-based clinical reminder systems for preventive care in the ambulatory setting. J Am Med Inform Assoc 1996;3:399-409.

20. Walsh JM, McPhee SJ. A systems model of clinical preventive care: an analysis of factors influencing patient and physician. Health Educ Q 1992;19:157-75.

21. Wagner EH. Chronic disease management: what will it take to improve care for chronic illness? Eff Clin Pract 1998;1:2-4.

22. Daly JM, Xu Y, Ely JW, Levy BT. A randomized colorectal screening intervention trial in the Iowa Research Network: study recruitment and baseline results. J Am Board Fam Med 2012;25:63-72.

23. Levy BT, Daly JM, Xu Y, Ely JW. Mailed fecal immunochemical tests plus education materials to improve colon cancer screening rates in Iowa Research Network (IRENE) practices. J Am Board Fam Med 2012;25:73-82.

24. Dillman DA. Mail and internet surveys: the tailored design method. 2nd ed. Hoboken, NJ: John Wiley \& Sons; 2007.

25. Levy BT, Nordin T, Sinift S, Rosenbaum M, James PA. Why hasn't this patient been screened for colon cancer? An Iowa Research Network study. J Am Board Fam Med 2007;20:458-68.

26. Vernon SW, Meissner H, Klabunde C, et al. Measures for ascertaining use of colorectal cancer screening in behavioral, health services, and epidemiologic research. Cancer Epidemiol Biomarkers Prev 2004; 13:898-905.

27. American Cancer Society. Get Tested for colon cancer. Here's how [DVD]. Atlanta, GA: American Cancer Society; 2008.

28. American Cancer Society. They know how to prevent colon cancer-and you can too. Take a look inside. No. 243900, rev. 01/08. Available from: http://www. cancer.org/acs/groups/content/@healthpromotions/ documents/document/acsq-020998.pdf. Accessed July 23, 2013.

29. Centers for Disease Control and Prevention (CDC). Colorectal cancer: basic fact sheet. Publication \#996949. Available from: http://www.cdc.gov/cancer/
colorectal/pdf/Basic_FS_Eng_Color.pdf. Accessed July 23, 2013.

30. Moerbeek M. Randomization of clusters versus randomization of persons within clusters: which is preferable? Am Statist 2005;59:172-9.

31. Zauber AG, Lansdorp-Vogelaar I, Knudsen AB, Wilschut J, van Ballegooijen M, Kuntz KM. Evaluating test strategies for colorectal cancer screening: a decision analysis for the U.S. Preventive Services Task Force. Ann Intern Med 2008;149:659-69.

32. Miller WR, Rollnick S. Motivational interviewing: helping people change. 3rd ed. New York: Guilford Press; 2003.

33. Roetzheim RG, Christman LK, Jacobsen PB, et al. A randomized controlled trial to increase cancer screening among attendees of community health centers. Ann Fam Med 2004;2:294-300.

34. Shannon KC, Sinacore JM, Bennett SG, Joshi AM, Sherin KM, Deitrich A. Improving delivery of preventive health care with the comprehensive annotated reminder tool (CART). J Fam Pract 2001;50: 767-72.

35. Sequist TD, Zaslavsky AM, Marshall R, Fletcher RH, Ayanian JZ. Patient and physician reminders to promote colorectal cancer screening: a randomized controlled trial. Arch Intern Med 2009;169:364-71.

36. Shojania KG, Jennings A, Mayhew A, Ramsay CR, Eccles MP, Grimshaw J. The effects of on-screen, point of care computer reminders on processes and outcomes of care. Cochrane Database Syst Rev 2009; (3):CD001096.

37. Arditi C, Rège-Walther M, Wyatt JC, Durieux P, Burnand B. Computer-generated reminders delivered on paper to healthcare professionals; effects on professional practice and health care outcomes. Cochrane Database Syst Rev 2012;12:CD001175.

38. Myers RE, Sifri R, Hyslop T, et al. A randomized controlled trial of the impact of targeted and tailored interventions on colorectal cancer screening. Cancer 2007;110:2083-91.

39. Daly JM, Levy BT, Merchant ML, Wilbur J. Mailed fecal-immunochemical test for colon cancer screening. J Community Health 2010;35:235-9.

40. Church TR, Yeazel MW, Jones RM, et al. A randomized trial of direct mailing of fecal occult blood tests to increase colorectal cancer screening. J Natl Cancer Inst 2004;96:770-80.

41. Walsh JM, Salazar R, Nguyen TT, et al. Healthy colon, healthy life: a novel colorectal cancer screening intervention. Am J Prev Med 2010;39:1-14.

42. Hewitson P, Ward AM, Heneghan C, Halloran SP, Mant D. Primary care endorsement letter and a patient leaflet to improve participation in colorectal cancer screening: results of a factorial randomised trial. Br J Cancer 2011;105:475-80.

43. Libby G, Bray J, Champion J, et al. Pre-notification increases uptake of colorectal cancer screening in all 
demographic groups: a randomized controlled trial. J Med Screen 2011;18:24-9.

44. van Roon AH, Hol L, Wilschut JA, et al. Advance notification letters increase adherence in colorectal cancer screening: a population-based randomized trial. Prev Med 2011;52:448-51.

45. Myers RE, Ross EA, Wolf TA, Balshem A, Jepson C, Millner L. Behavioral interventions to increase adherence in colorectal cancer screening. Med Care 1991;29:1039-50.

46. Hart AR, Barone TL, Gay SP, et al. The effect on compliance of a health education leaflet in colorectal cancer screening in general practice in central England. J Epidemiol Community Health 1997;51: 187-91.

47. Walsh JM, Karliner L, Burke N, Somkin CP, Pham LA, Pasick R. Physicians' approaches to recommending colorectal cancer screening: a qualitative study. J Cancer Educ 2010;25:385-90.

48. Dietrich AJ, Tobin JN, Cassells A, et al. Telephone care management to improve cancer screening among low-income women: a randomized, controlled trial. Ann Intern Med 2006;144:563-71.

49. Ling BS, Schoen RE, Trauth JM, et al. Physicians encouraging colorectal screening: a randomized controlled trial of enhanced office and patient management on compliance with colorectal cancer screening. Arch Intern Med 2009;169:47-55.

50. Segnan N, Senore C, Andreoni B, et al. Randomized trial of different screening strategies for colorectal cancer: patient response and detection rates. J Natl Cancer Inst 2005;97:347-57.

51. Whitlock EP, Lin JS, Liles E, Beil TL, Fu R. Screening for colorectal cancer: a targeted, updated systematic review for the U.S. Preventive Services Task Force. Ann Intern Med 2008;149:638-58.

52. Ornstein S, Nemeth LS, Jenkins RG, Nietert PJ. Colorectal cancer screening in primary care: translating research into practice. Med Care 2010;48: 900-6.

53. Klabunde C, Lanier D, Breslau ES, et al. Improving colorectal cancer screening in primary care practice: innovative strategies and future directions. J Gen Intern Med 2007;22:1195-205.

54. Levy BT, Daly JM, Schmidt EJ, Xu Y. The need for office systems to improve colorectal cancer screening. J Prim Care Community Health 2012;3:180-6.

55. Centers for Disease Control and Prevention (CDC). Vital signs: colorectal cancer screening among adults aged 50-75 years-United States, 2008. MMWR Morb Mortal Wkly Rep 2010;59:808-12.

56. Klabunde CN, Cronin KA, Breen N, Waldron WR, Ambs AH, Nadel MR. Trends in colorectal cancer test use among vulnerable populations in the United States. Cancer Epidemiol Biomarkers Prev 2011;20: 1611-21.

57. Fan L, Mohile S, Zhang N, Fiscella K, Noyes K. Self-reported cancer screening among elderly Medicare beneficiaries: a rural-urban comparison. J Rural Health 2012;28:312-9. 